\title{
Is magnification necessary to confirm visual inspection of cervical abnormalities? A randomized trial in Peru
}

\author{
Jennifer L. Winkler, ${ }^{1}$ Kristen Lewis, ${ }^{1}$ Roberto Del Aguila, ${ }^{2}$ Miguel Gonzales, ${ }^{3}$ \\ José Manuel Delgado, ${ }^{3}$ Vivien D. Tsu, ${ }^{1}$ and John W. Sellors ${ }^{1}$
}

Suggested citation

Winkler JL, Lewis K, Del Aguila R, Gonzales M, Delgado JM, Tsu VD, et. al. Is magnification necessary to confirm visual inspection of cervical abnormalities? A randomized trial in Peru. Rev Panam Salud Publica. 2008;23(1):1-6.

ABSTRACT Objectives. Cervical cancer is the leading cause of cancer death among women in developing countries. This study was designed to evaluate whether visual inspection with acetic acid and magnification (VIAM) improved confirmation of cervical lesions as compared to confirmation with visual inspection with acetic acid (VIA) without magnification when used by physicians.

Methods. From April-December 2004, women in San Martin, Peru, who were referred as VIA-positive by an "obstetriz" (a professional midwife with 6 years of university training) were randomized into two groups for confirmatory screening by a physician using either VIA or VIAM with an AviScope, ${ }^{\mathrm{TM}}$ a hand-held $4 \times$ magnification scope with a green light source. The reference standard for the presence or absence of cervical neoplasia was colposcopy and directed biopsy, as required.

Results. A total of 358 women participated in the study; 161 had a confirmatory examination with VIAM and 159 with VIA. Sensitivity for low- or high-grade lesions was $68 \%$ with VIA and $77 \%$ with VIAM, and specificity was $62 \%$ with VIA and $63 \%$ with VIAM; however, these differences were not statistically significant.

Conclusions. For settings where physician confirmation of cervical abnormalities identified through visual inspection is required and available, this study demonstrates that VIAM had no significant advantage over VIA.

Key words Uterine cervical neoplasms, diagnosis/screening, Peru.

Cervical cancer is the leading cause of cancer death among women in developing countries (1). In Peru, cervical cancer kills over 2600 women every year (1). While cytology-based cervical

PATH, Seattle, Washington, United States of America. Send correspondence to: Jennifer L. Winkler, 1455 NW Leary Way, Seattle, WA 98107, United States of America. Telephone: +01-206-285-3500 Fax: +01-206-285-6619; e-mail: jwinkler@path.org.

Pan American Health Organization, San José, Costa Rica.

Pan American Health Organization, Lima, Peru. screening programs have led to significant reductions in incidence and mortality from cervical cancer in developed countries, few organized screening programs exist in developing-country settings. Programs have often not been effectively implemented, and in many cases, testing has been of poor quality and has had limited population coverage (2). Screening programs that do exist often have not led to appropriate treatment. A study in Peru found that only $25 \%$ of women with abnormal cytology received appropriate followup care (3). Improved techniques for screening, confirmation of disease, and treatment could have an impact on reducing the mortality from this highly preventable disease.

Colposcopy, with directed biopsy as appropriate, is commonly used for diagnosis of a woman with a positive screening test or for clinical suspicion of other cervical abnormalities (4). A 
colposcopic examination is relatively expensive; it requires costly equipment and an operator with special training, and often generates costs for histopathology. In low-resource settings, many women who are referred for colposcopy reside many hours from colposcopy centers. Visual inspection with acetic acid and magnification (VIAM) using the AviScope ${ }^{\mathrm{TM}}$ (O'Ryan Industries, Vancouver, Washington, United States of America)-a hand-held, battery-powered, $4 \times$ magnification monocular scope with a green light source-has been proposed as a potential low-cost, more portable alternative to colposcopy in low-resource settings (5).

In San Martin, Peru, the Screening and Immediate Attention project (TATI-Tamizaje y Tratamiento Inmediato) employed visual inspection with acetic acid (VIA) for screening, and for those who were positive, VIAM with the AviScope ${ }^{\mathrm{TM}}$ to confirm the diagnosis prior to treatment with cryotherapy (6). In an analysis of over 5000 women screened, the positive predictive value of precancerous lesions in VIA-positive women was improved using VIAM (7), but since VIA screening was always performed by a midwife and VIAM was always performed by a doctor, it was unclear whether the apparent improvement in accuracy was due to the magnification or to the education/experience level of examiner. To answer this question, we conducted a randomized trial to compare the accuracy of confirmatory VIAM to that of VIA; both types of exams were performed by a local general physician on women referred with a positive VIA screening exam performed by an "obstetriz," a professional Peruvian midwife with 6 years of university training.

\section{MATERIALS AND METHODS}

The study ran from April-December 2004 to allow time for 400 women to be enrolled in the study. The sample size of 400 (200 participating in each arm of the trial) was calculated to detect a $15 \%$ increase in sensitivity for CIN $1+$ when using VIAM (power of 0.90 with a two-sided probability of alpha error of 0.05). Women 25-49 years of age from the three health networks in San Martin (i.e., San Martin, Moyobamba, and Rioja) were invited to participate in VIA screening campaigns. Women with positive VIA examinations by obstetrizes were randomized into two groups for confirmatory exam using VIA or VIAM performed by a physician. The study physician opened a sequentially-numbered opaque envelope that included a randomlyassigned slip of paper indicating whether the confirmatory exam was to be performed using VIA or VIAM. Study staff maintained a list of these assignments and confirmed during data entry that the physician had performed the assigned examination.

This randomized study was a substudy within the larger TATI project and used the same informed consent forms and data collection methods employed in the larger study described previously (7). The PAHO Human Subjects Protection Committee and the National Institute of Health of the Peruvian Ministry of Health approved the study.

For VIA examinations, the cervix was washed with a $5 \%$ acetic acid solution and, after a minute, was viewed with the naked eye (8). For VIAM, the cervix was washed with the acetic acid solution, but rather than using the naked eye to view the cervix as in VIA, the AviScope ${ }^{\text {TM }}$ was used (9).VIA and VIAM confirmatory results were classified as normal or abnormal. An abnormal VIA or VIAM result was defined as a slowly fading opaque acetowhite area with well-demarcated margins in the transformation zone near the squamo-columnar junction. Areas that were suspicious for cancer bled easily on contact and had an irregular, raised, ulceroproliferative surface (women with lesions suspicious for cancer were excluded from the study). All women participating in the study were referred to the study colposcopist (a gynecologic oncologist who traveled to the area from the National Institute of Neoplastic Diseases (INEN), the national cancer reference hospital, Peru) for a follow-up visit within a 90- day period following the confirmatory exam. The colposcopist was blinded to the group to which the women had been assigned.

\section{Provider characteristics}

Seven general physicians who were part of the larger TATI Project, working in the health networks of San Martin, Moyobamba, and Rioja, participated in the study. Five of the physicians had graduated from medical school 10-19 years prior to the study; one had graduated less than 10 years prior; and one had graduated more than 19 years prior. Four of the seven physicians had been trained in visual examination techniques 4 years prior to the study; three had been trained 3 years prior. Cumulative experience with visual inspection varied: three of the physicians were less experienced, having performed fewer than 300 visual examinations; and four of the physicians were more experienced, having performed more than 300 visual examinations.

\section{Inclusion/exclusion criteria}

To be included in the analysis, participants had to have a positive VIA examination by an obstetriz, a confirmatory visual examination (VIA or VIAM) completed by a physician, and a colposcopic examination. The confirmatory visual examination by a physician (included since physician confirmation of the obstetriz's visual inspection was standard practice in Peru) was to be completed within 90 days from a positive VIA screening exam, and the colposcopy examination within 90 days from the confirmatory exam. Women who were out of the 25-49 year age range, had previously had a positive Pap smear, or had a lesion suspicious for or recognized as cancer on VIA, were excluded from the study. Women who were identified as having invasive cancer were referred to INEN and their treatment costs were covered by the project. 


\section{Diagnosis}

Participants were considered negative for cervical intraepithelial neoplasia (CIN) and cancer if their biopsy was negative or if they had a negative colposcopy result (and therefore no biopsy was performed). Presence of CIN and cancer was assessed on the basis of histology. Histology was performed by a pathologist contracted by the project and blinded to the group to which women had been allocated. Results were analyzed using two thresholds: low- and high-grade combined (CIN $1+$ ) or high-grade only (CIN 2+). Since the goal of visual examinations is to identify precancerous lesions that can be treated before they develop into cancer, all cancers were excluded from analysis.

\section{Data management and analysis methods}

Data were entered into a Visual FoxPro 6.0 (Microsoft Inc., Washington, United States) database developed for this project and were analyzed using Intercooled Stata 8.2 (StataCorp LP, Texas, United States). The sensitivity, specificity, positive predictive value (PPV), negative predictive value (NPV), and 95\% confidence intervals (95\%CI) were calculated for confirmatory visual examinations with VIA and VIAM, using colposcopy and histology as the reference standard.

\section{RESULTS}

Of the 2906 women 25-49 years of age who were screened with VIA, 2393 were VIA-negative, 15 were referred directly to a colposcopist with a lesion suspicious for cancer, and 498 were VIA-positive. Of the 420 VIApositive women examined by a physician, 358 were also evaluated by a colposcopist (184 were examined with VIAM and 174 with VIA only). Of these, 320 (89\%) had a final diagnosis, 161 with VIAM and 159 with VIA. Of the 38 clients excluded from the analysis, two were excluded because they had cancer and 36 were colposcopy-

TABLE 1. Demographic and health characteristics of the 320 women allocated to the VIAM ${ }^{a}$ and the VIA ${ }^{b}$ confirmatory examination arms of the randomized trial, Peru, 2004

\begin{tabular}{|c|c|c|c|c|c|c|}
\hline \multirow[b]{2}{*}{ Characteristic } & \multicolumn{2}{|c|}{ VIAM } & \multicolumn{2}{|c|}{ VIA } & \multicolumn{2}{|c|}{ Total } \\
\hline & No. & $\%$ & No. & $\%$ & No. & $\%$ \\
\hline \multicolumn{7}{|l|}{ Age (in years) } \\
\hline 25-29 & 70 & 38 & 67 & 39 & 137 & 38 \\
\hline $30-34$ & 40 & 22 & 32 & 18 & 72 & 20 \\
\hline $35-39$ & 38 & 21 & 36 & 21 & 74 & 21 \\
\hline $40-44$ & 28 & 15 & 19 & 11 & 47 & 13 \\
\hline $45-49$ & 8 & 4 & 20 & 11 & 28 & 8 \\
\hline \multicolumn{7}{|c|}{ Years of education } \\
\hline 0 & 6 & 3 & 7 & 4 & 13 & 4 \\
\hline $1-6$ & 87 & 47 & 86 & 49 & 173 & 48 \\
\hline $7-11$ & 71 & 39 & 67 & 39 & 138 & 39 \\
\hline $12+$ & 20 & 11 & 14 & 8 & 34 & 9 \\
\hline \multicolumn{7}{|c|}{ Number of sexual partners } \\
\hline 1 or 2 & 154 & 84 & 137 & 79 & 291 & 81 \\
\hline 3 or 4 & 25 & 13 & 31 & 18 & 56 & 16 \\
\hline $5+$ & 5 & 3 & 6 & 3 & 11 & 3 \\
\hline \multicolumn{7}{|l|}{ Parity } \\
\hline 0 & 2 & 1 & 5 & 3 & 7 & 2 \\
\hline $1-3$ & 125 & 68 & 115 & 66 & 240 & 67 \\
\hline $4-7$ & 48 & 26 & 47 & 27 & 95 & 26 \\
\hline $8+$ & 9 & 5 & 7 & 4 & 16 & 5 \\
\hline \multicolumn{7}{|c|}{ Number of abortions } \\
\hline 0 & 114 & 62 & 107 & 62 & 221 & 62 \\
\hline 1 or 2 & 66 & 36 & 65 & 37 & 131 & 36 \\
\hline 3 or 4 & 4 & 2 & 2 & 1 & 6 & 2 \\
\hline
\end{tabular}

a VIAM: visual inspection with acetic acid and magnification. b VIA: visual inspection with acetic acid.

positive for CIN without a biopsy result (28 were CIN positive on colposcopy, but no biopsy was obtained; 5 biopsy reports were provided to clients directly and not reported to the study; 2 were insufficient samples, and 1 was reported as cervicitis). Among the 320 women with a final diagnosis, 281 were negative $(88 \%), 18$ had CIN 1 $(6 \%)$, and 21 had CIN 2/3 (6\%). Compared to women included in the analysis, women excluded from analysis were younger (mean of 30.5 vs. 33.7 years; $P=0.006$ ); were more likely to smoke currently or in the past $(11.1 \%$ vs. $1.6 \% ; P=0.001)$; and had fewer children (mean of 2.0 vs. $3.2 ; P=0.001$ ), but had similar education levels, numbers of abortions, prior Pap smears, sexual partners, and contraceptives used, and belonged to similar ethnic groups.

The average time between the screening and the confirmation was 25.6 days (standard deviation $(\mathrm{SD})=$ 38.9 ), with half of women returning within 9 days. The average time between a confirmatory and colposcopic examination was 21.2 days $(\mathrm{SD}=34.4)$, with half of the women returning within 7 days. Thirty-one women did not receive a confirmatory visit by a general physician within 90 days after a positive VIA examination, and 24 women did not receive a colposcopic examination within 90 days after a confirmatory examination. Since there was no significant difference in the proportion of women who remained positive on final diagnosis when seen within 90 days as compared to those seen after 90 days for both confirmatory $(P=0.74)$ and colposcopic examinations $(P=0.23)$, they were included in the analysis.

Women who received confirmatory examination with VIA and with VIAM had similar demographic and health characteristics (Table 1). Four percent of women had no formal education, $54 \%$ attended some primary, 39\% at- 
TABLE 2. Proportions of the 161 women in the VIAM ${ }^{a}$ arm and the 159 women in the VIA arm of the trial in the final diagnostic categories, Peru, 2004

\begin{tabular}{|c|c|c|c|c|c|c|c|c|c|c|}
\hline \multirow[b]{3}{*}{ Test } & & & \multicolumn{6}{|c|}{ Final disease status } & & \\
\hline & \multicolumn{2}{|c|}{ Negative } & \multicolumn{2}{|c|}{ CIN 1} & \multicolumn{2}{|c|}{$\mathrm{CIN} 2$} & \multicolumn{2}{|c|}{ CIN 3} & \multicolumn{2}{|c|}{ Total } \\
\hline & No. & $\%$ & No. & $\%$ & No. & $\%$ & No. & $\%$ & No. & $\%$ \\
\hline \multicolumn{11}{|l|}{ VIAM } \\
\hline Negative & 91 & 96 & 3 & 3 & 0 & 0 & 1 & 1 & 95 & 100 \\
\hline Positive & 53 & 80 & 4 & 6 & 4 & 6 & 5 & 8 & 66 & 100 \\
\hline \multicolumn{11}{|l|}{ VIA } \\
\hline Negative & 85 & 93 & 3 & 3 & 0 & 0 & 4 & 4 & 92 & 100 \\
\hline Positive & 52 & 78 & 8 & 12 & 2 & 3 & 5 & 7 & 67 & 100 \\
\hline
\end{tabular}

a VIAM: visual inspection with acetic acid and magnification.

b VIA: visual inspection with acetic acid.

TABLE 3. Sensitivity and specificity of VIAM ${ }^{\mathrm{a}}$ and VIA ${ }^{\mathrm{b}}$ using disease thresholds of $\mathrm{CIN}^{\mathrm{c}} 1+$ and CIN 2+, Peru, 2004

\begin{tabular}{|c|c|c|c|c|c|c|}
\hline Disease definition ${ }^{d}$ & Test & $n$ & $\begin{array}{l}\text { Sensitivity (\%) } \\
(95 \% \mathrm{Cl})^{\mathrm{e}}\end{array}$ & $\begin{array}{c}\text { Specificity (\%) } \\
(95 \% \mathrm{Cl})\end{array}$ & $\begin{array}{l}\operatorname{PPV}^{f}(\%) \\
(95 \% \mathrm{Cl})\end{array}$ & $\begin{array}{l}\text { NPVg }(\%) \\
(95 \% \mathrm{Cl})\end{array}$ \\
\hline \multirow[t]{2}{*}{ Low- or high-grade (CIN 1+) } & VIAM & 161 & $\begin{array}{c}77 \\
(50-93)\end{array}$ & $\begin{array}{c}63 \\
(55-71)\end{array}$ & $\begin{array}{c}20 \\
(11-31)\end{array}$ & $\begin{array}{c}96 \\
(90-99)\end{array}$ \\
\hline & VIA & 159 & $\begin{array}{c}68 \\
(45-86)\end{array}$ & $\begin{array}{c}62 \\
(53-70)\end{array}$ & $\begin{array}{c}22 \\
(13-34)\end{array}$ & $\begin{array}{c}92 \\
(85-97)\end{array}$ \\
\hline \multirow[t]{2}{*}{ High-grade only (CIN 2+) } & VIAM & 161 & $\begin{array}{c}90 \\
(56-100)\end{array}$ & $\begin{array}{c}62 \\
(54-70)\end{array}$ & $\begin{array}{c}14 \\
(6-24)\end{array}$ & $\begin{array}{c}99 \\
(94-100)\end{array}$ \\
\hline & VIA & 159 & $\begin{array}{c}64 \\
(31-89)\end{array}$ & $\begin{array}{c}60 \\
(51-67)\end{array}$ & $\begin{array}{c}11 \\
(4-20)\end{array}$ & $\begin{array}{c}96 \\
(89-99)\end{array}$ \\
\hline
\end{tabular}

a VIAM: visual inspection with acetic acid and magnification.

b VIA: visual inspection with acetic acid.

${ }^{c} \mathrm{CIN}$ : cervical intraepithelial neoplasia.

d Cancer excluded from performance results.

e $\mathrm{Cl}$ : confidence interval.

Positive predictive value.

${ }_{9}$ Negative predictive value.

tended some secondary, and only 9\% initiated education beyond secondary school. Sixty-seven percent of women in both groups had had 1-3 pregnancies. Thirty-eight percent of women reported having had at least one abortion. Ninety-nine of the participants were from the same mestizo ethnic group and $97 \%$ had never smoked (data not shown). There was no significant difference in the number of prior Pap smears between groups $(P=0.09)$, and approximately $74 \%$ of women had had at least one prior Pap smear.

Table 2 shows the distribution of confirmatory visual examination re- sults with VIA-only and with VIAM, by final disease status. Similar proportions of women are identified as positive with VIAM (41\%) as by VIA-only $(42 \%)(P=0.84)$. Women in the VIAonly group were more likely to have a clinical disease $(13.8 \%)$ than those in the VIAM group $(10.6 \%)$; the difference, however, was not significant $(P=0.37)$.

\section{Test performance}

Table 3 compares the test performance of confirmatory examinations performed with VIA and VIAM for the CIN $1+$ and CIN 2+ detection thresholds. For both thresholds, there were no statistically-significant differences in sensitivity or specificity based on the confirmatory examination performed. There were also no significant differences in sensitivity or specificity based on the number of examinations that the physician had performed (data not shown). Based on the sample size attained, this study had power of 0.80 to detect a difference in sensitivity of $15 \%$. The PPV for CIN $1+$ was $22 \%$ for confirmatory examinations with either VIA or VIAM while the PPV of VIA-only screening, without a followup confirmatory test, was $12.2 \%$ (95\%CI: 8.8-16.3\%).

\section{DISCUSSION}

This study indicates that when performed by a physician, VIAM was not significantly more accurate than VIA for confirming the presence of CIN in women referred with a positive VIA examination by a professional midwife. Not using VIAM to confirm disease status could simplify the organization of services considerably, as it would eliminate the need for an instrument, in this case an AviScope ${ }^{\mathrm{TM}}$, that must be in working order and available at the time of the confirmatory visit. During the course of the larger TATI project, a number of confirmatory visits were delayed when an AviScope $^{\mathrm{TM}}$ at the confirmatory site nearest to the client was out of order.

While confirmation with the VIAM device did not provide enough improvement over naked eye cervical visualization to be worth the investment and complexity, other options may be worth exploring. Some authors have argued that confirmation after positive VIA is not necessary, and treatment options like cryotherapy pose a small enough risk to the patient that it may be worthwhile to offer treatment to all screen-positive women. It has been argued that cryotherapy is safe and unlikely to harm women and eliminates loss to follow-up that occurs with referral for confirmatory examination (10). 
This study is limited in that, for ethical reasons, we were not able to perform four-quadrant biopsies on all women who were negative by visual exams and thus do not know how many truly positive women were falsely identified as negative. Since this study only followed women with positive visual inspection examinations, we cannot calculate the sensitivity or specificity for VIA (as this would require knowing the true status of the women who were identified as VIA negative), however, the PPV of VIA without follow-up confirmation (which can be calculated since all testpositive women were followed up with colposcopy and histology if indicated) would have been just $12 \%$ for low- or high-grade lesions, suggesting that a confirmatory exam could add value.

An earlier study of the AviScope ${ }^{\mathrm{TM}}$ in women in the United States referred to a colposcopy clinic because of abnormal cytology found the AviScope ${ }^{\mathrm{TM}}$ to be only moderately sensitive and specific (sensitivity of $60 \%$ and speci- ficity of 69\%) (11). However, an Indian study evaluating VIAM performed with the Magnivisualizer device (a $2.5 \times$ lighted scope) in a previously screened population found a sensitivity for high-grade lesions of $83 \%$ and a specificity of $94 \%$ (12). Sellors et al. suggest that while the performance of the AviScope ${ }^{\mathrm{TM}}$ prototype device was suboptimal as compared to colposcopy, a hand-held magnification device with better optics and illumination might be developed (9).

This study was powered to detect an increase in sensitivity of at least $15 \%$. In resource-poor environments, both sensitivity and specificity would need to be considerably better than VIA alone to warrant the increased expense and complexity of adding any device; and in this study VIAM did not provide that benefit. This study does not explore whether general physicians are better than other levels of health professionals (e.g., nurses) for performing the confirmatory step following a positive cervical screening. However, in Peru, only physicians are permitted to perform treatment with cryotherapy; therefore, if nurses were to perform confirmation, it would be best to co-locate services to reduce potential loss to follow-up.

This study demonstrates that physicians performing a confirmatory examination of a cervical lesion with VIAM had no significant advantage over simple VIA. However, it is not able to address the question of which would be greater: the loss of true positives due to an insensitive test or the loss to follow-up incurred by having a second provider confirm the initial screening. Modeling these trade-offs could elucidate these questions to better guide program planners in identifying viable strategies for organizing optimal cervical cancer prevention programs.

Acknowledgements. The authors acknowledge the generous support of the Bill \& Melinda Gates Foundation, through the Alliance for Cervical Cancer Prevention (ACCP), for making the study possible.

\section{REFERENCES}

1. Ferlay J, Bray F, Pisani P, Parkin D. GLOBOCAN 2002: Cancer incidence, mortality and prevalence worldwide [Version 2.0]. Lyon, France: IARC Press; 2004. [IARC CancerBase No. 5]

2. Sankaranarayanan R, Budukh AM, Rajkumar $R$. Effective screening programmes for cervical cancer in low- and middle-income developing countries. Bull World Health Organ. 2001;79(10):954-62

3. Gage JC, Ferreccio C, Gonzales M, Arroyo R, Huivin M, Robles SC. Follow-up care of women with an abnormal cytology in a lowresource setting. Cancer Detect Prev. 2003; 27(6):466-71.

4. Sellors JW, Sankaranarayanan R. Colposcopy and treatment of cervical intraepithelial neoplasia: A beginners' manual. Lyon, France: IARC Press; 2003.

5. Winkler JL, Tsu VD, Bishop A, Scott R, Sellors JW. Confirmation of cervical neoplasia using a hand-held, lighted magnification device. Int J Gynaecol Obstet. 2003;81(1):35-40.
6. Luciani S, Winkler J. Cervical cancer prevention in Peru: Lessons learned from the TATI demonstration project. Washington, D.C. PAHO; 2006.

7. Almonte M, Ferreccio C, Winkler JL, Cuzick J, Tsu V, Robles S, Takahashi R, Sasieni P. Cervical screening by visual inspection, HPV testing, liquid-based, and conventional cytology in Amazonian Peru. Int J Cancer. 2007;121(4): 796-802.

8. Carr KC, Sellors JW. Cervical cancer screening in low resource settings using visual inspection with acetic acid. J Midwifery Womens Health. 2004;49(4):329-37.

9. Sellors JW, Winkler JL, Kreysar DF. Illumination, optics, and clinical performance of a hand-held magnified visual inspection device (AviScope ${ }^{\mathrm{TM}}$ ): a comparison with colposcopy. J Acquir Immune Defic Syndr. 2004;37(Suppl 3):S160-6.

10. Gaffikin L, Blumenthal PD, Emerson M, Limpaphayom K. Safety, acceptability, and feasibility of a single-visit approach to cervical- cancer prevention in rural Thailand: a demonstration project. Lancet. 2003;361(9360): 814-20.

11. Parashari A, Singh V, Sehgal A, Satyanarayana L, Sodhani P, Gupta MM. Low-cost technology for screening uterine cervical cancer. Bull World Health Organ. 2000;78(8): 964-7.

12. Winkler JL, Tsu VD, Bishop A, Scott R, Sellors JW. Confirmation of cervical neoplasia using a hand-held, lighted magnification device. Int J Gynaecol Obstet. 2003;81(1):35-40.

Manuscript received on 22 January 2007. Revised version accepted for publication on 11 November 2007. 
RESUMEN Objetivos. En los países en desarrollo, el cáncer cervicouterino es la principal causa de muerte por cáncer en mujeres. Este estudio se diseñó para determinar si se puede mejorar la confirmación de lesiones cervicouterinas con la inspección visual con ácido

\section{¿Es necesaria la amplificación para confirmar los resultados de la inspección visual de alteraciones cervicouterinas? Ensayo aleatorizado en Perú} acético y amplificación (VIAM) en comparación con la inspección visual con ácido acético (VIA) sin amplificación, cuando ambas las realizan médicos generales.

Métodos. Las mujeres de San Martín, Perú, con diagnóstico positivo mediante VIA realizado por una obstetriz (enfermera graduada con seis años de entrenamiento universitarios) entre abril y diciembre de 2004 se dividieron aleatoriamente en dos grupos para el diagnóstico confirmatorio realizado por médicos generales mediante VIA o VIAM, este último con un AviScope ${ }^{\mathrm{TM}}$, un dispositivo manual con lente monocular de amplificación $4 \mathrm{X}$ y fuente luz verde. Como método estándar de referencia para definir la presencia o ausencia de neoplasia cervicouterina se emplearon la colposcopia y la biopsia dirigida, según el caso.

Resultados. En el estudio participaron 358 mujeres, de ellas 161 pasaron la confirmación por VIAM y 159 por VIA. La sensibilidad para las lesiones de bajo y alto grados fue de $68 \%$ con VIA y de $77 \%$ con VIAM, mientras la especificidad fue de $62 \%$ por VIA y de $63 \%$ por VIAM; estas diferencias no tuvieron significación estadística.

Conclusiones. Se demostró que la VIAM no presentó ventajas significativas sobre la VIA en los casos en que se requiere y está disponible la confirmación de las lesiones del cuello uterino por un médico general.

Palabras clave Neoplasmas del cuello uterino, diagnóstico, cribado, Perú. 